\title{
GASTROSTOMY UNDER PARAVERTEBRAL BLOCK IN HIGH-RISK PATIENTS WITH ESOPHAGEAL CANCER - TWO CASE REPORTS
}

\author{
Miroslav Zupčić ${ }^{1}$, Anđelko Korušić ${ }^{1}$, Stjepan Barišin ${ }^{1}$, Jasminka Peršec ${ }^{2}$, Igor Nikolić3, \\ Sandra Graf Zupčićc ${ }^{4}$, Vjekoslav Jeleč ${ }^{5}$, Viktor Đuzel ${ }^{6}$ and Zlatko Vlajčić ${ }^{7}$
}

${ }^{1}$ Josip Juraj Strossmayer University of Osijek, Osijek School of Medicine, Dubrava University Hospital, Clinical Department of Anesthesiology, Resuscitation and Intensive Care Medicine, Zagreb, Croatia; ${ }^{2}$ Clinical Department of Anesthesiology, Resuscitation and Intensive Care Medicine, Dubrava University Hospital, Zagreb, Croatia; ${ }^{3}$ Josip

Juraj Strossmayer University of Osijek, Osijek School of Medicine, Dubrava University Hospital, Clinical

Department of Surgery, Zagreb, Croatia; ${ }^{4}$ Josip Juraj Strossmayer University of Osijek, Sveti Duh University Hospital, Clinical Department of Neurology, Zagreb, Croatia; ${ }^{5}$ osip Juraj Strossmayer University of Osijek, Osijek

School of Medicine, Dubrava University Hospital, Department of Neurosurgery, Zagreb, Croatia; ${ }^{6}$ Barking, Havering and Redbridge University Hospitals NHS Trust, Department of Anaesthesia, London, United Kingdom; ${ }^{7}$ Josip Juraj Strossmayer University of Osijek, Osijek School of Medicine, Dubrava University Hospital, Clinical Department of Plastic, Reconstructive and Aesthetic Surgery, Zagreb, Croatia

\begin{abstract}
SUMMARY - Here we present two cases of gastrostomy insertion via laparotomy in patients with malignant esophageal disease. Patients were ASA (American Society of Anesthesiologists) physical status III and IV. The patients presented as very high risk for general anesthesia, so we decided to use unilateral left sided paravertebral block (PVB) on four thoracic levels along with contralateral local infiltration at the gastrostomy insertion site. We present two cases, one of them a 57-year-old male ASA III patient scheduled for a gastrostomy procedure due to esophageal cancer with infiltration of the trachea. We also present a case of a 59-year-old male patient, ASA IV status, scheduled for the same procedure due to advanced esophageal cancer with a fistula between the left main bronchus and the esophagus and metastases in the left lung. The paravertebral space was identified with the use of an $8 \mathrm{Hertz}(\mathrm{Hz})$ linear ultrasound probe and a nerve stimulator. Paravertebral block was successfully used for insertion of a gastrostomy, thereby enabling adequate anesthesia and perioperative analgesia without hemodynamic or respiratory complications.
\end{abstract}

Key words: Local anesthetics; Anesthesia; Analgesia; Gastrostomy; Esophageal cancer

\section{Introduction}

Some techniques of regional anesthesia may provide adequate surgical anesthesia for operations of the upper abdominal region. The most commonly described technique is thoracic epidural anesthesia ${ }^{1}$. This technique

Correspondence to: Zlatko Vlajčic, $M D, P h D$, Dubrava University Hospital, Clinical Department of Plastic, Reconstructive and Aesthetic Surgery, Av. Gojka Šuška 6, HR-10000 Zagreb, Croatia E-mail: zvlajcic@kbd.hr

Received February 5, 2017, accepted April 3, 2017 results in bilateral symmetric anesthesia, but also in sympathetic blockade and is often accompanied by hemodynamic instability. There is also the possibility of causing an epidural hematoma or nerve damage ${ }^{1,2}$. Paravertebral block (PVB) is achieved by injection of local anesthetic in a space just lateral to the spinal canal, where the spinal nerves emerge from the intervertebral foramina. PVB results in ipsilateral segmental, sensory and sympathetic nerve blockade ${ }^{3}$. PVB gains on popularity due to the analgesic effects comparable with that 
provided by a thoracic epidural technique but with significant advantages because of fewer complications such as hypotension, respiratory complications and urinary retention. More recently, there has been renewed interest in this technique for the treatment of acute and chronic pain. Because of the ability to provide longlasting unilateral anesthesia, PVBs have been successfully used to provide analgesia for multiple thoracic and abdominal procedures ${ }^{3,4}$. Here, we present two cases of patients categorized as the American Society of Anesthesiologists (ASA) status III and IV, scheduled for gastrostomy insertion due to malignant neoplastic processes. For these patients with serious cardiac and pulmonary disorders, both neuraxial and general endotracheal anesthesia presented an extremely high risk due to the inability of compensation for consequent hemodynamic response, so the option of PVB seemed the most appropriate mode of anesthesia.

\section{Case Reports}

\section{Case 1}

A 57-year-old male patient was scheduled for a gastrostomy procedure due to esophageal cancer and impossibility of passing food or water. The patient was of ASA III status with hypertension and cachexia as comorbidities. Investigations revealed that he could not swallow solid foods for several months and had difficulty swallowing water and pureed food. Multislice computerized tomography (MSCT) showed an advanced neoplastic process in the upper and middle esophagus, which extended in cranio-caudal direction from the lower cornua of the thyroid cartilage to the aortic arch. The lesion was inseparable from the vertebral bodies and encompassed over $50 \%$ of the circumference of the adjoining trachea with tracheal deviation to the right side. Fiberoptic bronchoscopy showed a fixated left vocal cord during respiration and phonation, with impossible passage distally from the vocal cords, while cytology revealed a squamous cell cancer of the esophagus. Due to the failed esophagogastroduodenoscopy (OGD) and impossible percutaneous endoscopic gastrostomy (PEG), there was an indication for open surgical gastrostomy via laparotomy.

\section{Case 2}

A 59-year-old male patient was scheduled for open surgical gastrostomy due to advanced esophageal cancer of the middle third of the esophagus accompanied by aphagia and cachexia. He was of ASA IV status, with a MSCT confirmed fistula between the left main bronchus and esophagus, and metastases in the left lung. An echocardiogram (ECHO) showed permanent atrial fibrillation, dilatative cardiomyopathy, and an ejection fraction of $30 \%$, moderate mitral and tricuspid regurgitation with a defect in the interatrial septum. Laboratory findings showed low prothrombin time (40\%) due to anticoagulant therapy with warfarin.

After admission to the perioperative unit, the patients were monitored with noninvasive blood pressure monitoring (NIBP), electrocardiogram (ECG), peripheral pulse oxymetry $(\mathrm{SpO} 2)$ and an intravenous cannula was put in. After skin infiltration with $1 \mathrm{~mL}$ of $2 \%$ lidocaine (Lidocaine ${ }^{\circledR}$, Belupo, Koprivnica, Croatia), an ultrasound guided intra-arterial cannula was inserted into the radial artery for invasive blood pressure monitoring. One of the patients already had a central venous catheter inserted on the ward, through which he received parenteral nutrition, while we found it useful for intraoperative central venous pressure (CVP) monitoring and drug administration through the suitable ports. After positioning the patients in the sitting position and under aseptic technique, we detected the paravertebral space with an $8 \mathrm{Hertz}(\mathrm{Hz})$ linear ultrasound probe at a depth of $4.5 \mathrm{~cm}$ in the left thoracic side. For this procedure, we used a GE Healthcare (Logiq Medical Ultrasound System, Wauwatosa, USA) ultrasound probe and a nerve simulator (Stimuplex HNS 12, B. Braun Melsungen AG, Germany) with a nerve stimulating needle (Stimuplex $\mathrm{D}^{\circledR}, \mathrm{B}$. Braun Melsungen AG, Germany) of $22 \mathrm{G}$ width and $10 \mathrm{~cm}$ length. To detect the vicinity of the paravertebral space, the neurostimulator was set at the initial value of $2 \mathrm{~Hz}$ and decreased to $0.5 \mathrm{~Hz}$ with persistent muscle contractions. With intermittent aspiration, we applied the local anesthetic $0.5 \%$ levobupivacaine (Chirocaine ${ }^{\circledR}$, Abbott Laboratories, Dublin, Ireland) on the left side of the spine, at four levels, Th7, Th8, Th9 and Th10 (3 mL per level). For anesthesia of the right side of the laparotomy incision, the surgeon locally infiltrated a solution of $5 \mathrm{~mL} 0.5 \%$ levobupivacaine plus $2 \mathrm{~mL} 2 \%$ lidocaine and $3 \mathrm{~mL}$ normal saline. After block application, both patients were continually monitored for heart rate (HR), pulse oxygen saturation $(\mathrm{SpO} 2)$, invasive arterial blood pressure (IBP), and CVP in the patient with significant cardiac disease. All parameters were of a satisfactory reading. 
The block was tested to warm and cold and pin-prick testing, on the left side from Th6 to Th10 dermatomes. Sensory blockade occurred after 20 minutes in the first case and after 18 minutes in the second case. Because we applied small doses of local anesthetics at multiple levels, laterally to the spine, there was no catheter placement involved and therefore we did not use a testing dose, in accordance with the literature ${ }^{3,5}$. By combining ultrasound and nerve stimulation techniques, we maximized our efficiency. During surgical preparation and after surgical cleaning of the operating area, the surgeon performed local infiltration of the incision line 10 minutes prior to incision, with the solution as mentioned previously, $5 \mathrm{~mL} 0.5 \%$ levobupivacaine plus $2 \mathrm{~mL} 2 \%$ lidocaine and $3 \mathrm{~mL}$ normal saline. During both procedures, the patients were continually monitored for HR, $\mathrm{SpO} 2$, IBP (along with CVP in the patient with significant cardiac disease) and sedated with low dose propofol in continuous infusion $(30-35 \mu \mathrm{g} / \mathrm{kg} / \mathrm{min})$. In the first patient (Case 1), we recorded the values of $\mathrm{HR}$ from 70 to 80 beats/min, IBP (systolic pressure from 120 to $130 \mathrm{~mm} \mathrm{Hg}$, diastolic pressure from 60 to 70 $\mathrm{mm} \mathrm{Hg}$ ); $\mathrm{SpO} 2$ was $97 \%$ with oxygen supplementation at $6 \mathrm{~L} / \mathrm{min}$ flow via a non-rebreathing mask. In the second patient (Case 2), we recorded the values of HR from 80 to 90 beats/min, IBP (systolic pressure from 130 to $140 \mathrm{~mm} \mathrm{Hg}$, diastolic pressure from 70 to 80 $\mathrm{mm} \mathrm{Hg}$ ); CVP was from 12 to $14 \mathrm{~mm} \mathrm{Hg}$, and $\mathrm{SpO} 2$ was $98 \%$ with oxygen supplementation at $6 \mathrm{~L} / \mathrm{min}$ flow via a non-rebreathing mask. There were no significant changes in hemodynamic values of HR and IBP during and after application of the thoracic PVB in either patient. Both patients had a respiratory frequency from 12 to 18 breaths per minute. In the second patient, during skin retraction of the right side of the laparotomy line, the patient had a feeling of slight pain and discomfort, which was eliminated with a bolus of $100 \mu \mathrm{g}$ of intravenous fentanyl (Fentanyl ${ }^{\circledR}$, Janssen, Belgium). The operation was completely uneventful. Surgery lasted for 30 minutes in the first and 35 minutes in the second case. Both patients were admitted postoperatively to the recovery room with continuous monitoring of vital functions as in theatre. After 40 minutes of stable parameters, the arterial lines were removed and the patients were transferred to the ward with postoperative instructions to the ward staff. In the first case, the sensory blockade lasted for 9.5 hours after block administration, or 8.5 hours after surgery. In the second case, sensory blockade lasted for 8 hours after block administration or 7 hours after surgery. During the first 24 hours of the postoperative period, the pain score was monitored according to the visual analogue scale (VAS) every three hours. The first patient had a VAS score of 3 and did not require any additional analgesia, while the second patient had a VAS score of 5 after 7 hours postoperatively and was administered 75-mg intravenous diclofenac sodium (Voltaren, Pliva, Zagreb, Croatia) infusion in $100 \mathrm{~mL}$ of saline solution over 15 minutes. At postoperative follow up, 24 hours after the operation, both patients were very satisfied with the anesthesia treatment and no complications occurred.

\section{Discussion}

Paravertebral block is achieved by injection of local anesthetic in the space just lateral to the spinal canal, where the spinal nerves emerge from the intervertebral foramina, and results in ipsilateral segmental, sensory and sympathetic nerve blockade ${ }^{3}$. PVB gains on popularity due to the analgesic effects comparable with that provided by the thoracic epidural technique but with significant advantages because of fewer complications such as hypotension, respiratory complications and urinary retention ${ }^{3,4}$. In these two cases, we showed that PVB at multiple levels, with contralateral local infiltration of the incision site, was a safe technique of anesthesia, with a significant reduction in the possible perioperative complications in patients with cardiac and pulmonary disorders ${ }^{6,7}$. Many papers have presented the use of PVB alone or in combination with general anesthesia for surgical procedures in the abdominal or thoracic regions ${ }^{3,5-12}$. Coveney et al..$^{8}$ have presented PVB alone as an efficient and reliable anesthetic technique for radical mastectomy in comparison to general anesthesia. Tahiri et al. ${ }^{9}$ examined the results from 11 studies comparing PVB with general anesthesia and showed significantly lower pain scores during the first 6 postoperative hours and lower perioperative analgesic consumption in patients with PVB. Belinkoff et al. ${ }^{10}$ conducted a study on 100 patients investigating multilevel intercostal block at Th6-Th11 in combination with general or spinal anesthesia. In this study, emphasis was on the left or right sided intercostal blockade for certain upper abdominal procedures. Kelly et al. ${ }^{11}$ demonstrated the efficiency of continuous thoracic paravertebral block (TPVB) comparing it to thoracic epidural anal- 
gesia for thoraco-abdominal esophageal surgery. There are very few scientific publications about TPVB and hemodynamic stability in upper abdominal surgery. Most publications are based on open cholecystectomies in patients with cardiac and pulmonary disorders ${ }^{6,7}$. In their study of open cholecystectomy, Serpetinis et al. ${ }^{6}$ used multilevel TPVB at Th6-Th9 levels in eight patients with cardiopulmonary comorbidities. In this technique, they administered $5 \mathrm{~mL} 0.75 \%$ ropivacaine per level and did not compromise the hemodynamic stability of the patients while at the same time with placing epidural catheter at Th7 level, they had an excellent 24-hour postoperative analgesia result. Beyaz et al. ${ }^{7}$ report on two cases of open cholecystectomy, one of them with significant cardiopulmonary comorbidities. In both patients, they applied TPVB as an anesthetic technique, with $20 \mathrm{~mL} 0.5 \%$ levobupivacaine at Th-7 level. The patient with cardiopulmonary comorbidity had a significant fall in heart rate (bradycardia of 40 beats/min occurred at $5 \mathrm{~min}$ after block administration) and blood pressure (hypotension of 65/44 $\mathrm{mm} \mathrm{Hg} 45$ min after block administration), most probably due to the anesthetic spreading into the epidural space ${ }^{7}$. Therefore, it should be noted that single shot paravertebral administration of local anesthetics can cause significant problems such as failed block or epidural spreading of local anesthetics, due to the sagittal spread of the local anesthetic ${ }^{13}$. In order to avoid significant hemodynamic alterations, we applied a technique of giving smaller doses of long-lasting local anesthetics at multiple paravertebral levels, with skin infiltration of the puncture site. By combining ultrasound and nerve stimulation techniques, we maximized the efficiency of TPVB.

\section{Conclusion}

The administration of a multilevel unilateral TPVB with local infiltration of the contralateral side to the incision site proved to be a safe and effective procedure in patients with significant cardiopulmonary comorbidities and compromised airways. The cases presented are unique in the literature because they show that using this technique, with minimal sedation, we achieved adequate anesthesia and analgesia without compromising hemodynamic stability.

\section{References}

1. Parthasarathy S, Ravishankar M, Aravindan U. Total radical gastrectomy under continuous thoracic epidural anaesthesia. Indian J Anaesth. 2010;54:358-9, doi: 10.4103/0019-5049.68385

2. Horlocker TT, Wedel DJ. Neurologic complications of spinal and epidural anesthesia. Reg Anesth Pain Med. 2000;25: 83-98.

3. Karmakar MK. Thoracic paravertebral block. Anesthesiology. 2001;95:771-80.

4. Ding X, Jin S, Niu X, Ren H, Fu S, Li Q. A comparison of the analgesia efficacy and side effects of paravertebral compared with epidural blockade for thoracotomy: an updated metaanalysis. PLoS One. 2014;9:e96233, https://doi.org/10.1371/journal.pone.0096233

5. Tighe SQM, Greene DM, Rajadurai N. Paravertebral block. Contin Educ Anaesth Crit Care Pain. 2010;10:133-7, https://doi.org/10.1053/bjaceaccp/mkq029

6. Serpetinis I, Bassiakou E, Xanthos T, Baltatzi L, Kouta A. Paravertebral block for open cholecystectomy in patients with cardiopulmonary pathology. Acta Anaesthesiol Scand. 2008; 52:872-3.

7. Beyaz SG, Özocak H, Ergönenç T, Erdem AF. The thoracic paravertebral block performed for open cholecystectomy operation in order to anesthesia: two cases. Anesth Essays Res. 2014;8:239-42, doi: 10.4103/0259-1162.134521

8. Coveney E, Weltz CR, Greengrass R, Iglehart JD, Leight GS, Steele SM, et al. Use of paravertebral block anesthesia in the surgical management of breast cancer: experience in 156 cases. Ann Surg. 1998;227:496-501.

9. Tahiri Y, Tran de QH, Bouteaud J, Xu L, Lalonde D, Luc M, et al. General anesthesia versus thoracic paravertebral block for breast surgery: a meta-analysis. J Plast Reconstr Aesthet Surg. 2011;64:1261-9, doi: 10.1016/j.bjps.2011.03.025.

10. Belinkoff S. Prolonged intercostal nerve block in upper abdominal operations. Ann Surg. 1948;127:136-43.

11. Kelly FE, Murdoch JA, Sanders DJ, Berrisford RG. Continuous paravertebral block for thoraco-abdominal oesophageal surgery. Anaesthesia. 2005;60:98-9.

12. Moussa AA. Opioid saving strategy: bilateral single-site thoracic paravertebral block in right lobe donor hepatectomy. Middle East J Anaesthesiol. 2008;19:789-801.

13. Naja MZ, Ziade MF, E1 Rajab M, El Tayara K, Lönnqvist PA Varying anatomical injection points within the thoracic paravertebral space: effect on spread of solution and nerve blockade. Anaesthesia. 2004;59:459-63, doi: 10.1111/j.1365-2044.2004.03705.x 
Sažetak

\title{
PRIMJENA PARAVERTEBRALNOG BLOKA ZA POSTAVLJANJE GASTROSTOME KOD VISOKO RIZIČNIH BOLESNIKA S KARCINOMOM JEDNJAKA - DVA PRIKAZA SLUČAJA
}

\author{
M. Zupčic, A. Korušic, S. Barišin, J. Peršec, I. Nikolic, S. Graf Zup̌̌icic, V. Jeleč, V. Đuzeli Z. Vlajǔcić
}

Prikazujemo dva slučaja postavljanja gastrostome laparotomijskim putem kod bolesnika s malignom bolesti jednjaka. Bolesnici su prema Američkom anesteziološkom društvu (American Society of Anesthesiologists, ASA) klasificirani kao ASA status III i IV. Zbog vrlo visokog rizika za primjenu opće anestezije prikazanim bolesnicima odlučili smo primijeniti prsni paravertebralni blok na četiri razine s nasuprotnom lokalnom infiltracijom mjesta postavljanja gastrostome. Prikazujemo dva slučaja; jedan je bio 57-godišnji ASA III bolesnik predviđen za postavljanje gastrostome zbog karcinoma jednjaka s infiltracijom traheje. Također prikazujemo 59-godišnjeg ASA IV bolesnika predviđenog za isti zahvat zbog uznapredovalog karcinoma jednjaka s fistulom između glavnog lijevog bronha i jednjaka uz metastaze na lijevom plućnom krilu. Paravertebralni prostor je identificiran primjenom ultrazvučne linearne sonde od $8 \mathrm{Hertza}(\mathrm{Hz})$. Paravertebralni blok je uspješno primijenjen za postavljanje gastrostome omogućavajući time zadovoljavajuću anesteziju i perioperacijsku analgeziju bez hemodinamskih i respiracijskih komplikacija.

Ključne riječi: Lokalni anestetici; Anestezija; Analgezija; Gastrostoma; Tumori jednjaka 